\title{
Online educational resources for orthopaedic residency-a narrative review
}

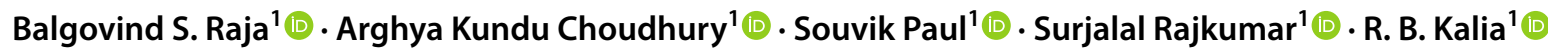

Received: 15 April 2021 / Accepted: 25 May 2021 / Published online: 2 June 2021

(c) SICOT aisbl 2021

\begin{abstract}
Purpose Residency programs in the medical education field are considered the keystone in the development of aptitude and skills required for practice. With the worldwide current scenario of the COVID-19 pandemic, there has been a shift in the paradigm especially in the teaching of the residents from face-to-face classes to more and more online sessions. The purpose of this study is to present a compendium of knowledge-providing sites, smartphone applications (apps), YouTube channels, and podcasts that can provide better online resource management for students in the field of orthopaedics.

Methods Search terms were used for making a list of various online resources which can be of help during orthopaedic residency. An initial list of the selected websites, smartphone apps, podcasts, and YouTube channels was made. The corresponding author with years of teaching experience and faculty for post-graduate and fellowship training programs then selected the final list.

Results A list of 16 websites with brief points on their content and online address along with the availability of free or paid content was identified as being appropriate. A total of 39 apps available for android/apple smartphones, nine podcasts, and 11 YouTube channels were also identified as being extremely useful and have been discussed elaborately in this article.

Conclusion Online educational tools are of immense importance in imparting adequate knowledge to an orthopaedic resident and act as an adjunct to conventional teaching methods. This article focuses on presenting various online educational resources in a simple yet concise way, which may be beneficial for the current generation of residents especially in this current time of unprecedented COVID-19 pandemic.
\end{abstract}

Keywords Online tools · Websites · Smartphone apps · Podcasts · YouTube channels · Orthopaedic residency $\cdot$ Educational resources

\author{
R. B. Kalia \\ roopkalia2003@yahoo.com \\ Balgovind S. Raja \\ balgovindraja@gmail.com \\ Arghya Kundu Choudhury \\ arghyakunduchoudhury@gmail.com \\ Souvik Paul \\ 1900.souvik@gmail.com \\ Surjalal Rajkumar \\ drsurjalalrajkumar@gmail.com \\ 1 Department of Orthopaedics, All India Institute of Medical \\ Sciences, Rishikesh, India
}

\section{Introduction}

Residency programs in the medical education field are considered to be the keystones in the development of aptitude and skills required for practice. The education that residents or students imbibe during their residency ushers them forward to face the difficulties that they may encounter in the future and prepares them with problem-solving skills. Various methods of teaching exist in the curriculum [1]. These may be face-to-face classes, didactic lectures, group discussions, webinars, or conferences [1]. The years one needs to spend in a residency program differs from country to country but the essence of education remains the same [2]. The coronavirus disease-2019 (COVID-19) pandemic without a doubt has created a big hole in the residency programs all over the world with restrictions imposed in the form of social distancing and curtailment of routine surgery 
[3-6]. Face-to-face classes and case presentations have seen a drastic decrease in usage limiting the student's learning opportunities [3, 7, 8]. Moreover, the decreased volume of surgery has also made hands-on training and learning more difficult $[8,9]$.

With the current scenario of the COVID-19 pandemic, there has been a shift in the paradigm especially in the teaching of the residents $[10,11]$. Earlier, face-to-face interaction was considered the gold standard for medical education, and the need for maintaining up-to-date knowledge in the field was made possible by subscription to various online specialty-specific journals [12]. The skills needed for surgery were obtained from assisting surgeries first-hand and learning from the masters. Other than these, learning from seminars, journal clubs, hands-on training in cadaveric labs, and surgical skill labs were the usual norm in various surgical residency programs $[12,13]$. Recently, online educational tools and platforms such as Google Meet, Microsoft Teams, and Zoom have been increasingly used for knowledge sharing and the faculty, as well as the residents alike, are using these platforms extensively [14]. Although faceto-face educational activities remain valuable [15], there has been consensus about spreading infections during these serious times. Online tools such as websites with resources relevant to orthopaedics [16], podcasts, smartphone applications (apps), and YouTube channels are all good sources of information and study material for the budding residents $[8,17,18]$. With the vast number of sites, apps, and varied options available online, it is difficult to select the one with good content, usefulness, and functionality.

Orthopaedics is the branch that deals with the diseases of the bones and soft tissues in general. Just as in other specialties, orthopaedics also lays special emphasis on the education of residents. The invention of smartphones and the easy accessibility of the internet over the past few decades have increased the availability of resources that one can access for study [19]. The sheer number of sites and resources makes it difficult to choose and decreases the probability for the residents and budding surgeons to identify the ones with quality and usefulness. The purpose of this study is to present a compendium of knowledge-providing sites, smartphone apps, YouTube channels, and podcasts that can provide better resource management and be valuable for students in the field of orthopaedics.

\section{Materials and methods}

The study was conducted over three months from November 2020 to January 2021. The roles of the authors were defined before the study was conducted. The first and second authors were responsible for the initial search and preliminary list development. The third and fourth authors were involved in the final selection which was reviewed by the fifth author. Four online resources were searched for orthopaedic content and their usefulness. These included the online websites with orthopaedic information useful for residents, smartphone apps that have tools helpful for residents, podcasts that focus on academics, and YouTube channels that had videos on orthopaedic topics and surgical procedures. The inclusion criteria used were English language as the communicating medium, resources directed for orthopaedic learning, videos of surgical exposure or implants, and lectures. Online resources that focused on patient education were excluded.

The search term used for online websites was "orthopaedics" AND "learning" in the Google search engine with advanced search settings kept as language - English, region - any region, last update - anytime, terms appearing - in link to the page, show explicit results, file type - any type and usage type - not filtered by license. The resources searched that were directed with an aim for academics or can be used as an educational tool for orthopaedics residents were selected. The smartphone apps were searched in the Google Play Store and the App Store for iPhone. The search terms used in combination were Orthopaedic/Orthopedic(s), orthopaedic surgery, musculoskeletal, bones, and fracture. The apps searched were listed with a focus on their content, functionality, rating, and tools available for academics or surgical planning. Podcasts were searched in iTunes, Google Play Music, and Spotify with search terms "Orthopaedic/Orthopedic(s) podcasts". Podcasts that shared educational resources were selected. YouTube was also searched for channels that are dedicated to academics and learning surgical skills in orthopaedics using the search terms "orthopaedics learning/orthopaedics", "orthopaedic surgery", and "academics in orthopaedics". Those channels with less than three thousand subscribers were excluded. Contents of these YouTube channels were scrutinized based on patient education specific or surgeon/resident directed. Only channels with educational materials related to orthopaedic surgery catering to the interests of a physician or trainee residents were included.

An initial list of the selected websites, smartphone apps, podcasts, and YouTube channels was made. The third and fourth authors who are part of post-graduation and fellowship programs then selected the final list, which was reviewed and approved by the fifth author. The data were collected in Microsoft (MS) Excel sheet initially and due to the descriptive nature of the current study, no comparative analysis was considered.

\section{Results}

The online search of websites delivered 27,900 results. An initial list of 489 websites that had orthopaedic resources was made and out of this, 13 sites were chosen. Three sites 
that were not obtained in the initial search results were added by a manual search, making a total list of 16 websites (Fig. 1). The complete list of the websites with a brief point on their content and address along with the availability of free or paid contents is presented in Table 1.

The search for smartphone apps in the Google Play Store and Apple Store delivered 41 and 129 results, respectively. Out of these, 53 apps were selected for the initial list. The final list was then subsequently selected and contained a total of 39 apps. Table 2 describes the apps available in smartphones or iPads that residents can take advantage of in learning key concepts.

The podcasts search delivered a total of 22 results. The final list contained nine podcasts which are detailed in Table 3. The total number of results during YouTube search could not be calculated as search results in YouTube do not show the volume. A thorough search was done using the criteria and an initial list of 30 channels was made. The final list after a thorough review gave 11 results. These are listed in Table 4.

\section{Discussion}

The COVID-19 pandemic has brought forward an unexpected dilemma in the field of medical education especially in the surgical branches. The influx of a large number of COVID-19 patients into the health care setup had led to an overburden on the existing medical infrastructure. Moreover, with the need to limit the social interaction between individuals, the residency programs have been compelled to reinvent themselves to continue imparting quality learning experiences to the residents. Pertinent to human character, the need for improvisation leads to the development of newer methods to impart training. The medical education field is dynamically changing to adapt to the new normal. Alternative modes of education and the use of online resources for the betterment and knowledge sharing are being increasingly adopted.

A large number of orthopaedic websites [16] are often one click away and are easily available using smartphones and laptops or on personal computers. With the widespread
Fig. 1 Flowchart showing the search process for selecting online websites

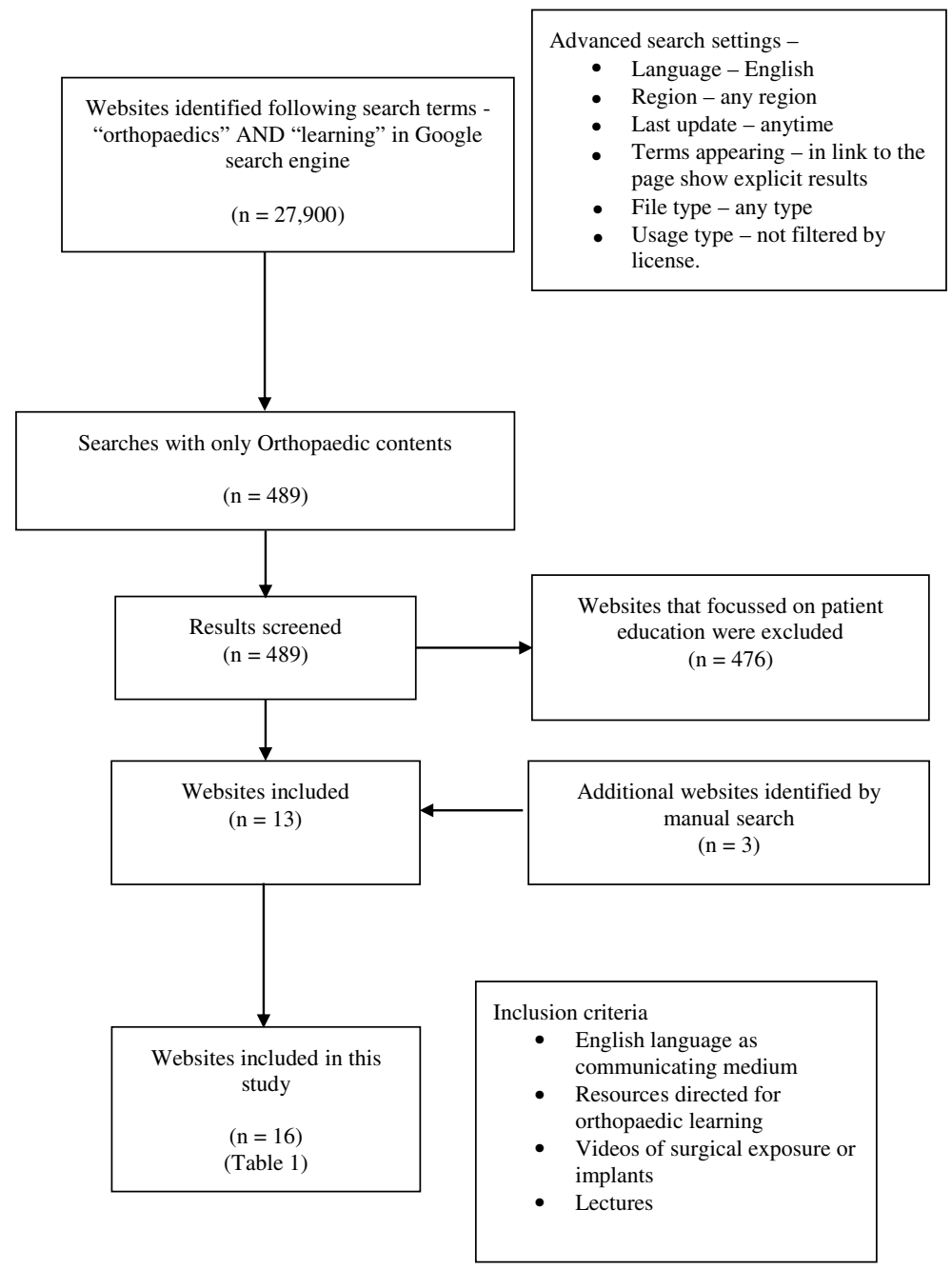


Table 1 List of various websites catering orthopaedic knowledge

\begin{tabular}{lll}
\hline Sl. no & Address & Description \\
\hline 1 & https://www.orthobullets.com/ & - A free online learning website \\
& - Comprehensive knowledge on various ortho- \\
& paedic topics including anatomy, pathology, \\
& basic sciences, trauma, joint reconstruction, \\
& arthroscopy, paediatrics, foot and ankle, hand \\
& and techniques for surgery \\
& - Provides MCQs on various topics for pre- \\
& mium members \\
& - User-friendly with up-to-date knowledge and \\
& attractive design \\
& New additions: \\
& PEEK (a personalised adaptive learning \\
& system) \\
& PASS (a teaching evaluation and report- \\
& ing platforms for academic institutions)-for \\
& premium users
\end{tabular}

2 https://www.wheelessonline.com/

\section{Paid/free}

Free

Premium membership (paid)

required for MCQs and

advanced features

An online orthopaedics textbook presented by Free

Duke University Medical Centre's Division of

Orthopaedic Surgery delivers

- Basic knowledge on various orthopaedic

topics and disaster preparedness

- Well structured

- Quality of the data not suited to everyone's style

- Insufficient videos and pictures

- Good references for further study

- Commercial website

$£ 58.75$ for 1 year

- Excellent source for knowledge for the residents and practicing physicians alike

- Large variety of topics, which includes anatomy to advanced topics including multiple specializations with detailed explanations

- Provides for the paid customers the option for MCQs and courses including FRCS Orth training, trauma skills, and multidisciplinary clinical examination course

- Well-designed and comprehensive with authority

- However, the cost of membership may deter many and topics need to be updated

- A unique website focused on academics

- Enriches basics knowledge from anatomy to super speciality

- Talks and presentations from prominent faculty made available free of cost for easy learning

- The site navigation: simple with first class content and updated on a regular basis

- Allows the users to post questions to the editors, promptly answered

- For the postgraduates and budding surgeons, gives links for the available training programs active at present and MCQs are free

- Provides basic anatomy about muscle origin and insertion

- Good pictorial representations of joints, muscles, nerves, blood vessels, and surface anatomy

- Discrepancy in the data 
Table 1 (continued)

\section{Sl. no Address}

6 http://www.bartleby.com/107/

http://www.netanatomy.com/

8 https://www.aaos.org/

9 https://www.vumedi.com/

10 https://aotrauma.aofoundation.org/ https://global-help.org/

\section{Description}

Paid/free

- Online version of Grey's anatomy

- Free website for studying bone or muscle or nerve anatomy

- The interface is not user-friendly

- An educational website that addresses radiographic anatomy, cross-sectional anatomy, and gross anatomy

- Available through an institutional subscription only

- Website of American Association of Orthopaedic Surgeons

- Provides a wide range of tools and online resources

- Offers evidence-based guidelines for the majority of orthopaedic conditions

Provides options on career centre and orthopaedic calendar

- Options for online learning and orthopaedic video theatre given

- A video education platform

- Free to use with simple user interface

- Provides videos (lecture) on all orthopaedic topics of relevance, multiple surgical technique videos

- Freshens up basic knowledges and updates

- The AO Foundation

- Excellent interface for the viewers

- Provides knowledge regarding the orthopaedic surgical exposures, techniques, and the implants

- Excellent-quality pictures and the videos: a boon to the residents and the surgeons alike

- Up-to-date knowledge on implants and procedures to a particular bone

- Provides details of the various academic courses it has to offer along with an online peer learning resource for the interested

- Free online medical library focused on child Free health

- Offers excellent resource materials, acclaimed articles and videos on various paediatric orthopaedic topics from trauma, evaluation, infections, management, tumours, neuromuscular diseases, sports injuries, and rehabilitation

- User-friendly interface and well-organised content

Free

\section{Free}

Paid

Learning tools are for a premium

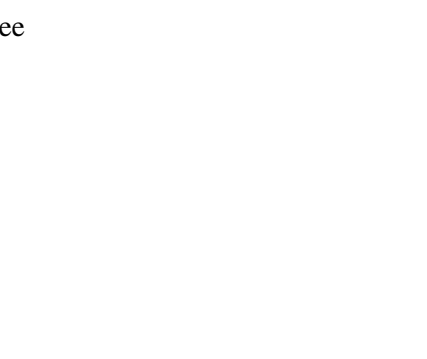


Table 1 (continued)

\begin{tabular}{|c|c|c|c|}
\hline S1. no & Address & Description & Paid/free \\
\hline 12 & https://jbjs.org & $\begin{array}{l}\text { - The Journal of Bone \& Joint Surgery website } \\
\text { - Information with evidence-based numerous } \\
\text { articles } \\
\text { - Easily accessed and viewed } \\
\text { - Offers a plethora of options to the budding } \\
\text { orthopods with JBJS reviews, JBJS case } \\
\text { connector, JBJS surgical techniques and JBJS } \\
\text { open access journals } \\
\text { - The JBJS clinical classroom is an online } \\
\text { adaptive learning program, focuses on } 10 \\
\text { orthopaedic subspecialties in the areas of } \\
\text { sports medicine, adult hip reconstruction, } \\
\text { adult knee reconstruction, spine, shoulder } \\
\text { and elbow, hand and wrist, foot and ankle, } \\
\text { paediatrics, basic sciences, and pathology and } \\
\text { ethics }\end{array}$ & $299 \$$ for clinical classroom \\
\hline 13 & $\begin{array}{l}\text { https://journals.lww.com/clinorthop/pages/ } \\
\text { default.aspx }\end{array}$ & $\begin{array}{l}\text { - Clinical Orthopaedics and Related Research }{ }^{\circledR} \\
\text { - Publication of The Association of Bone and } \\
\text { Joint Surgeons }{ }^{\circledR} \\
\text { - Vast number of articles in the orthopaedic } \\
\text { specialities } \\
\text { - Simple interface with accessible archives }\end{array}$ & Free \\
\hline 14 & $\begin{array}{l}\text { https://www.jnjmedicaldevices.com/en-EMEA/ } \\
\text { companies/depuy-synthes\#ourportfolio }\end{array}$ & $\begin{array}{l}\text { - Website of Johnson and Johnson } \\
\text { - Multiple operative techniques and videos } \\
\text { - Implant details and brochures }\end{array}$ & Free \\
\hline 15 & https://www.arthrex.com/ & $\begin{array}{l}\text { - Official website of the Arthrex company } \\
\text { - Techniques, surgical videos, implant bro- } \\
\text { chures, and recent articles } \\
\text { - Knowledge on orthobiologics }\end{array}$ & Free \\
\hline 16 & https://www.orthoracle.com/ & $\begin{array}{l}\text { - Online e-learning surgery atlas } \\
\text { - Full of practical information validated for } \\
\text { surgeons and residents } \\
\text { - High-resolution images of various orthopae- } \\
\text { dic procedures, details on the steps starting } \\
\text { from disease overview, indications, setup, } \\
\text { operative techniques, postoperative protocol, } \\
\text { implants, and results } \\
\text { - Costly }\end{array}$ & 7 euros/month \\
\hline
\end{tabular}

Words in bold type indicate special salient points of the websites

usage of internet facilities around the world, it has become easier for residents to access these websites within a few moments. This kind of electronic resource utilization has been seen throughout other specialized branches of medicine [20] as well as surgical [21] residents, indicating the recent trend of incorporation of technology in learning. Unlike the situations in the past where the residents need to consult a senior or need to visit the library to enhance his/her knowledge, it has become a lot more easier and effective method to look in these sites for information. The study by Sherman et al. [22] revealed that $44.9 \%$ of the online educational contents were easily accessible through an internet search. It was also shown by Rogers et al. that Orthobullets has a very high rate of usage $(99.5 \%)$ among their study subset of residents [17]. A lot of websites have resources for orthopaedic training but only a select few have high quality with an excellent interface, user-friendly nature, design, and functionality. Websites like Orthobullets, Orthopaedic principles, AOtrauma foundation website, VuMedi, and Global Health.org all have an excellent user interface and highquality material that act as adjuncts to the resident training programs [17].

The invention of smartphones has revolutionized the scenario of education and the present generation of residents are more technologically advanced and can easily access the content on the internet [19]. There exist numerous apps that residents can access for e-learning. The functionality of these apps exceeds far more than the websites. There exist apps which one can measure angles, plan surgeries, learn about anatomy, learn academics, keep one updated with recent articles and implant details, etc. But, there are concerns regarding the content and validity of the information 
Table 2 List of various smartphone applications (apps)

\begin{tabular}{|c|c|c|c|c|}
\hline S1 no & Applications & Platform & Functionality & Paid/free \\
\hline \multicolumn{5}{|c|}{ Applications useful for measurement of angles } \\
\hline 1 & CJ Ortho & Mac/iPhone/iPad/Android & $\begin{array}{l}\text { Goniometer tool, tool for fracture classifica- } \\
\text { tion, tool for clinical scores for joints and } \\
\text { data storage }\end{array}$ & Free \\
\hline 2 & Angulus: Measure angles on images/videos & Android & Tool for angle measurement & Free \\
\hline 3 & Scoliguage & Mac/iPad/iPhone & Tool for angle measurement & $0.99 \$$ \\
\hline 4 & Angle Meter 360 & Mac/iPad/iPhone & Tool for angle measurement & Free \\
\hline \multicolumn{5}{|c|}{ Applications useful for surgical planning in orthopaedics } \\
\hline 5 & PeekMed® & $\mathrm{Mac} / \mathrm{PC} / \mathrm{iPad}$ & $\begin{array}{l}\text { Tools for osteotomy, templating, planning and } \\
\text { fracture reduction }\end{array}$ & Paid \\
\hline 6 & Surgimap & Mac/iPhone/iPad Android & $\begin{array}{l}\text { Tool for viewing patient database and images, } \\
\text { tool for measurement and planning surgery }\end{array}$ & Free \\
\hline 7 & mediCAD & $\mathrm{PC} / \mathrm{Mac} /$ web browsers & $\begin{array}{l}\text { Tool for measurement, angle calculation, } \\
\text { planning and various templates especially in } \\
\text { total joint replacement. It also has tools for } \\
\text { deformity correction and 3D printing }\end{array}$ & Paid \\
\hline 8 & TraumaCad Mobile & iPad & $\begin{array}{l}\text { Tools to plan total joint replacement. Tools for } \\
\text { measurement of angles and length }\end{array}$ & Free \\
\hline 9 & Bone Ninja & iPad & $\begin{array}{l}\text { Tool for preoperative planning of osteotomies } \\
\text { and limb reconstruction }\end{array}$ & $\begin{array}{l}\$ 49.9 \\
\text { Or } \\
\text { Rs.4499 }\end{array}$ \\
\hline \multicolumn{5}{|c|}{ Applications useful for academics in orthopaedics } \\
\hline 10 & $\begin{array}{l}\text { AO Surgery Reference/Clinical (technique } \\
\text { guide) }\end{array}$ & AS/PS & $\begin{array}{l}\text { It provides the residents with accurate knowl- } \\
\text { edge regarding the fractures of all the bones, } \\
\text { its AO classification, and the treatment } \\
\text { Moreover, the app provides detailed knowledge } \\
\text { regarding the surgical exposures, the tips for } \\
\text { fracture reduction, the implants need to be } \\
\text { used, and their rationale }\end{array}$ & Free \\
\hline 11 & $\begin{array}{l}\text { CORE - Clinical Orthopedic Exam*/Clinical } \\
\text { (exam) }\end{array}$ & iPad/iPhone/PS & $\begin{array}{l}\text { An excellent app to study the clinical examina- } \\
\text { tion in orthopaedics. It provides users with } \\
\text { more than } 200 \text { clinical tests and their refer- } \\
\text { ences }\end{array}$ & $\begin{array}{l}39.9 \$ \text { or } \\
\text { Rs. } 3499 /-\end{array}$ \\
\hline 12 & Essential Anatomy 5 & AS & $\begin{array}{l}\text { A tool to learn the anatomy of human body. It } \\
\text { offers annotations and clear texts }\end{array}$ & Paid \\
\hline 13 & Grey's anatomy & AS & Excellent app for learning anatomy & Free \\
\hline 14 & Bullets & AS and PS & App from Orthobullets website & $\begin{array}{l}\text { Free, but } \\
\text { modules } \\
\text { paid }\end{array}$ \\
\hline 15 & iOrtho*/Clinical (exam) & AS/PS & $\begin{array}{l}\text { It focuses on the clinical examination in ortho- } \\
\text { paedics. Numerous test which are described } \\
\text { along with references, supported with images, } \\
\text { videos and statistics }\end{array}$ & Paid \\
\hline 16 & Conceptual orthopedics & AS/PS & $\begin{array}{l}\text { An app for learning academics. It offers multi- } \\
\text { ple videos and lectures on basic and advanced } \\
\text { topics in orthopaedics }\end{array}$ & Paid \\
\hline 17 & OrthoGuidelines (AAOS) & PS and AS & $\begin{array}{l}\text { Guideline recommendations by orthopaedic } \\
\text { disease, specialty, keyword, strength of evi- } \\
\text { dence, and/or stage of care }\end{array}$ & Free \\
\hline 18 & Skeletal System Pro III & iPad/iPhone & $\begin{array}{l}\text { An anatomy-based app which provides 3D } \\
\text { models with tools for identifying each } \\
\text { muscle, bone, nerve, and artery. It also } \\
\text { provides cross-sectional anatomy and videos } \\
\text { demonstrating various surgical procedures } \\
\text { and common pathologies }\end{array}$ & AS: $\$ 9.99$ \\
\hline 19 & MSK Radiology 4 U & iPhone/iPad & $\begin{array}{l}\text { Case-based teaching of the musculoskeletal } \\
\text { radiology }\end{array}$ & Paid \\
\hline
\end{tabular}


Table 2 (continued)

Sl no Applications

Platform

Functionality

Paid/free

Applications useful for fracture classification

20 Fracture Classification HD

AS/PS

21 AO/OTA Fracture Classification

AS/PS

22 Fracture Classification (FC)

AS/PS

23 Ortho Traumapedia

AS/PS

24 RealWorld Orthopaedics

AS

Applications useful for learning surgical skills

25 RealWorld Procedures

iPad/iPhone

AS/PS

iPad

BoneDoc

iPhone/iPad

Applications useful for patient education

29 My Knee Guide

iPad/iPhone

iPad/iPhone

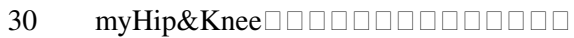

31 Arthrosurface

iPad

32

PhysioMed

iPad/iPhone

AS ( iPad)/PS

iPad

Applications useful for implant details

\begin{tabular}{|c|c|c|}
\hline 34 & Acumed & iPad \\
\hline 35 & Arthrex surgeon app & AS and PS \\
\hline 36 & 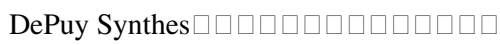 & $\mathrm{iPad} / \mathrm{iPhone}$ \\
\hline 37 & 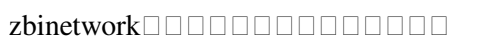 & $\mathrm{iPad} / \mathrm{iPhone}$ \\
\hline & Stryker Op Tech Live & $\mathrm{iPad} / \mathrm{iPhone}$ \\
\hline
\end{tabular}

Helps in fracture classification Paid

Tool helpful in classification of fractures. It Free contains numerous images and X-rays which would be helpful

Tool helpful in fracture classification Free

An interesting app for the residents which Paid offers basic knowledge regarding bones, fractures, dislocations and treatment

Simple user friendly interface allows users to quickly access the contents

App for musculoskeletal radiology

Paid

Simple tutorials for procedures

The app provides videos for a limited number of orthopaedic procedures that a resident or budding surgeon can find useful

An app to access an entire video content of AAOS. The list encompasses almost all of the specialities

Case-based scenarios for orthopaedic trauma. The user can have access to library of cases, reference cases, and expert opinions. The app allows users to download the material which can help in surgical training and preventing the mistakes

An interactive and educational orthopaedic surgery tool which helps in simulating orthopaedic surgery. A methodological approach can be studied by the residents

A resource useful for patients undergoing total knee replacement. It provides the users with real-world stories, expectations, and the requirements that patients need to follow each day

Helps in patient education post-surgery $\quad$ Free

A resourceful app which helps patients understand normal and abnormal knee kinematics. Helpful for patients with knee pathologies

An app with a focus on physiotherapy. There are multiple injuries listed and the physiotherapy protocol is devised based on rationale The exercises list encompasses almost all exercises and images and links to videos are also present for patient education

Contains text on various topics of the upper extremity with focus on diagnosis, treatment and the overall management

Techniques, videos, implant details available

Free Techniques, videos, implant details available Techniques and implant details

Free

Free offered

Techniques and implant information
Free

Free

Free

Free
Free

Free 
Table 2 (continued)

\begin{tabular}{lllll}
\hline S1 no & Applications & Platform & Functionality & Paid/free \\
\hline 39 & Orthofix ABS & iPad & Treatment options for various fractures & Free \\
\hline
\end{tabular}

$A S$, Apple Store; $P S$, Google Play Store

Table 3 List of online podcasts

\begin{tabular}{|c|c|c|c|}
\hline S1. no & Address & Content & Address \\
\hline 1 & $\begin{array}{l}\text { White Coat Coaching I Orthopedic Resi- } \\
\text { dency Advice }\end{array}$ & $\begin{array}{l}\text { - Made for undergraduate students by ortho } \\
\text { residents } \\
\text { - Built to empower next generation of } \\
\text { orthopods } \\
\text { - There are } 28 \text { interviews to date, which } \\
\text { would help the students to understand } \\
\text { orthopaedics in a better way from multiple } \\
\text { perspectives }\end{array}$ & https://whitecoatcoaching.com/podcasts/ \\
\hline 2 & $\begin{array}{l}\text { Ortho Eval Pal I Optimizing Orthopedic } \\
\text { Evaluations and Management Skills }\end{array}$ & $\begin{array}{l}\text { - Paul Marquis P.T delivers the podcast } \\
\text { - Focused on orthopaedic evaluation and } \\
\text { management skills for various scenarios } \\
\text { - It has } 168 \text { clippings as of now }\end{array}$ & https://www.buzzsprout.com/325448 \\
\hline 3 & BJJ Podcasts 24 & $\begin{array}{l}\text { - Offers exclusive interviews from authors } \\
\text { of the selected papers published in the BJJ } \\
\text { - Subscription through iTunes }\end{array}$ & $\begin{array}{l}\text { https://online.boneandjoint.org.uk/bjj/podca } \\
\text { sts }\end{array}$ \\
\hline 4 & The Orthobullets Podcast & $\begin{array}{l}\text { - Podcast from bullets team } \\
\text { - Contains more than } 500 \text { voice recordings } \\
\text { pertaining to orthopaedic conditions and } \\
\text { their management }\end{array}$ & $\begin{array}{l}\text { https://www.orthobullets.com/Site/Podcasts/ } \\
\text { PodcastsList?p=2 }\end{array}$ \\
\hline 5 & Ankle Surgery Update & $\begin{array}{l}\text { - A podcast aimed to keep listeners updated } \\
\text { about the recent advancements in the field } \\
\text { of ankle surgery }\end{array}$ & https://anklesurgeryupdate.buzzsprout.com/ \\
\hline 6 & Foot and Ankle Orthopaedics & $\begin{array}{l}\text { - Official podcast channel of American Foot } \\
\text { and Ankle society } \\
\text { - Multiple recordings to make listeners } \\
\text { understand the recent advancements and } \\
\text { rationale of procedures }\end{array}$ & $\begin{array}{l}\text { http://footandankle.sage-publications.libsy } \\
\text { npro.com/ }\end{array}$ \\
\hline 7 & $\begin{array}{l}\text { SAGE Orthopaedics I The American Jour- } \\
\text { nal of Sports Medicine }\end{array}$ & $\begin{array}{l}\text { - Podcast from SAGE for orthopaedics } \\
\text { - Provides recordings on the recent articles } \\
\text { published by the publisher }\end{array}$ & $\begin{array}{l}\text { http://sageorthopaedics.sage-publications. } \\
\text { libsynpro.com/ }\end{array}$ \\
\hline 8 & JBJS Podcast & $\begin{array}{l}\text { - It provides the highlights of recent issues } \\
\text { of JBJS }\end{array}$ & https://jbjs.org/media.php \\
\hline 9 & Arthroscopy Podcast Library & $\begin{array}{l}\text { - From The Journal of Arthroscopy and } \\
\text { Related surgery } \\
\text { - Short radio recordings listing the recent } \\
\text { articles published in the journal }\end{array}$ & $\begin{array}{l}\text { https://www.arthroscopyjournal.org/podca } \\
\text { st-archive-2020 }\end{array}$ \\
\hline
\end{tabular}

shared. It is upon the user to ascertain whether the information provided is credible or not. One can use these apps based on the publisher's reputation. The apps of the AAOS, Orthobullets, and surgical planning apps such as Surgimap, MediCAD, TraumaCad, AO group, Stryker, Acumed, and Arthrex are of special mention wherein the details are trustworthy [17, 23-25].

Similar to smartphone apps, YouTube has become the medium of sharing videos. As high as $86 \%$ of the respondents suggested they were most commonly used in the study by Rapp et al. [26]. Also, video-based education has been emphasized for surgical training [27] and the effectiveness of YouTube as a surgical teaching tool has been already described [28]. One can access the videos of seminars, lectures, surgical exposure videos, and various surgical techniques according to their need. Hence, it would be very useful for the residents to refer to these selected channels for gaining adequate knowledge and information whenever required. 


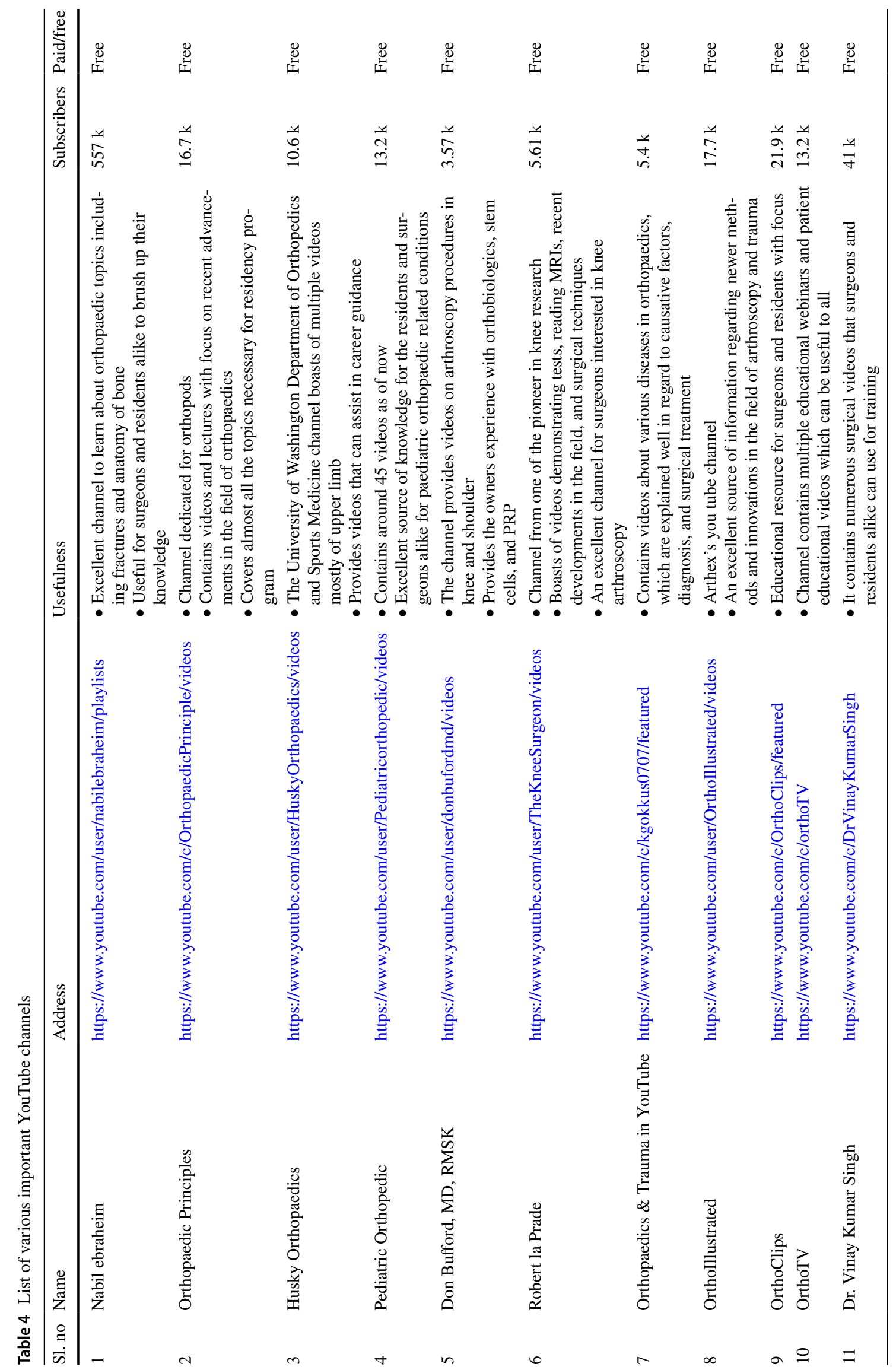


Podcasts refer to episodic series of spoken word digital audio files that a user can download to their device for easy listening (Wikipedia). Most of the podcasts can be accessed by streaming apps such as iTunes or Spotify. Orthopaedic podcasts that are helpful in learning are very few. Mostly these podcasts are for patient education and are not directed towards the education of the budding physicians. Orthobullets podcasts seem to contain the maximum educational audio clippings among the lot and are more precise with the knowledge it imparts. It becomes an easy additional option for the residents [29] to access these online audio lecture clippings whenever required.

Although the present study highlights various online orthopaedic learning resources concisely, it has some limitations worth mentioning. Being a narrative review, it becomes less important than a systematic review which is much more superior according to evidence-based medicine. One should always strive for a systematic review but the immense number of websites and channels in YouTube make it an exhaustible task. The final selections were made by experienced surgeons on the basis of their assessment. There may be bias in not selecting a few other relevant online educational tools.

\section{Conclusion}

Online educational tools are of immense importance in imparting adequate knowledge to an orthopaedic resident and acts as an adjunct to conventional teaching methods. With the technological advancements and easy accessibility in modern times, they are gradually becoming more and more acceptable among the group of young residents and trainees. This article focuses on presenting various online educational resources in a simple yet concise way, which may be beneficial for the current generation of residents and trainees in orthopaedics.

\section{Declarations}

Ethics approval Approval from the institutional ethics committee was not required for this review article.

Informed consent Informed consent was not required for this review article.

Conflict of interest The authors declare no competing interests.

\section{References}

1. Stambough JB, Curtin BM, Gililland JM et al (2020) The past, present, and future of orthopedic education: lessons learned from the COVID-19 pandemic. J Arthroplast 35(7S):S60-S64. https:// doi.org/10.1016/j.arth.2020.04.032

2. Sarmiento A (2008) On the education of the orthopedic resident. Indian J Orthop 42(3):241-244. https://doi.org/10.4103/00195413.41847

3. Ellison EC, Spanknebel K, Stain SC et al (2020) Impact of the COVID-19 pandemic on surgical training and learner well-being: report of a survey of general surgery and other surgical specialty educators. J Am Coll Surg 231(6):613-626. https://doi.org/10. 1016/j.jamcollsurg.2020.08.766

4. Zagra L, Faraldi M, Pregliasco F et al (2020) Changes of clinical activities in an orthopaedic institute in North Italy during the spread of COVID-19 pandemic: a seven-week observational analysis. Int Orthop 44:1591-1598. https://doi.org/10.1007/ s00264-020-04590-1

5. Luengo-Alonso G, Pérez-Tabernero FG-S, Tovar-Bazaga $\mathrm{M}$ et al (2020) Critical adjustments in a department of orthopaedics through the COVID-19 pandemic. Int Orthop 44:1557-1564. https://doi.org/10.1007/s00264-020-04647-1

6. Scarlat MM, Mavrogenis AF (2020) Orthopaedic surgery during COVID pandemic and consequent changes in our professional environment. Int Orthop 44:1607-1609. https://doi.org/10.1007/ s00264-020-04781-w

7. Malhotra R, Gautam D, George J (2020) Orthopaedic resident management during the COVID-19 pandemic - AIIMS model. J Clin Orthop Trauma 11:S307-S308. https://doi.org/10.1016/j. jcot.2020.05.001

8. Megaloikonomos PD, Thaler M, Igoumenou VG et al (2020) Impact of the COVID-19 pandemic on orthopaedic and trauma surgery training in Europe. Int Orthop 44:1611-1619. https://doi. org/10.1007/s00264-020-04742-3

9. Jain VK, Vaishya R (2020) COVID-19 and orthopaedic surgeons: the Indian scenario. Trop Doct 50:108-110. https://doi.org/10. 1177/0049475520921616

10. Barik S, Paul S, Kandwal P (2020) Insight into the changing patterns in clinical and academic activities of the orthopedic residents during COVID-19 pandemic: a cross-sectional survey. Knee Surg Sports Traumatol Arthrosc 28:3087-3093. https://doi.org/10. 1007/s00167-020-06274-0

11. Upadhyaya GK, Jain VK, Iyengar KP, Patralekh MK, Vaish A (2020) Impact of COVID-19 on post-graduate orthopaedic training in Delhi-NCR. J Clin Orthop Trauma 11:S687-S695. https:// doi.org/10.1016/j.jcot.2020.07.018

12. Wolf BR, Britton CL (2013) How orthopaedic residents perceive educational resources. Iowa Orthop J 33:185-190

13. Stirling ER, Lewis TL, Ferran NA (2014) Surgical skills simulation in trauma and orthopaedic training. J OrthopSurg 9.https:// doi.org/10.1186/s13018-014-0126-Z

14. Kogan M, Klein SE, Hannon CP, Nolte MT (2020) Orthopaedic education during the COVID-19 pandemic. J Am Acad Orthop Surg 28(11):e456-e464. https://doi.org/10.5435/ JAAOS-D-20-00292

15. Figueroa F, Figueroa D, Calvo-Mena R et al (2020) Orthopedic surgery residents' perception of online education in their programs during the COVID-19 pandemic: should it be maintained after the crisis? Acta Orthop 91(5):543-546. https://doi.org/10. $1080 / 17453674.2020 .1776461$

16. Gallacher P, Roach R (2008) Orthopaedic trainee resources online. Ann R Coll Surg Engl 90:536-537

17. Rogers MJ, Zeidan M, Flinders ZS et al (2019) Educational resource utilization by current orthopaedic surgical residents: a nation-wide survey. JAAOS Glob Res Rev 3.https://doi.org/10. 5435/JAAOSGlobal-D-19-00041

18. Tarpada SP, Morris MT, Burton DA (2016) E-learning in orthopedic surgery training: a systematic review. J Orthop 13:425-430. https://doi.org/10.1016/j.jor.2016.09.004 
19. Parekh SG, Nazarian DG, Lim CK (2004) Adoption of information technology by resident physicians. Clin Orthop 421:107-111. https://doi.org/10.1097/01.blo.0000126865.22310.59

20. Edson RS, Beckman TJ, West CP et al (2010) A multi-institutional survey of internal medicine residents' learning habits. Med Teach 32:773-775. https://doi.org/10.3109/01421591003692698

21. Davis JS, Garcia GD, Wyckoff MM et al (2013) Knowledge and usability of a trauma training system for general surgery residents. Am J Surg 205:681-684. https://doi.org/10.1016/j.amjsurg.2012. 07.037

22 Sherman NC, Sorenson JC, Khwaja AM, DeSilva GL (2020) The content and accessibility of orthopaedic residency program websites. JBJS Open Access 5(4):e20.00087. https://doi.org/10.2106/ JBJS.OA.20.00087

23. van Royen BJ (2020) Preoperative planning and the use of free available software for sagittal plane corrective osteotomies of the lumbar spine in ankylosing spondylitis. Orthop Res Rev 12:171182. https://doi.org/10.2147/ORR.S275860

24. Efe T, El Zayat BF, Heyse TJ et al (2011) Precision of preoperative digital templating in total hip arthroplasty. Acta Orthop Belg 77:616-621

25. Bayraktar V, Weber M, von Kunow F et al (2017) Accuracy of measuring acetabular cup position after total hip arthroplasty: comparison between a radiographic planning software and threedimensional computed tomography. Int Orthop 41:731-738. https://doi.org/10.1007/s00264-016-3240-1

26. Rapp AK, Healy MG, Charlton ME et al (2016) YouTube is the most frequently used educational video source for surgical preparation. J Surg Educ 73:1072-1076. https://doi.org/10.1016/j.jsurg. 2016.04.024

27. Ahmet A, Gamze K, Rustem M, Sezen KA (2018) Is video-based education an effective method in surgical education? A systematic review. J Surg Educ 75:1150-1158. https://doi.org/10.1016/j. jsurg.2018.01.014

28. Nowicki P (2019) Multimedia use in orthopedic surgery education. Orthopedics 42:246-248. https://doi.org/10.3928/0147744720190820-01

29. Schöbel T, Zajonz D, Melcher P et al (2020) Podcasts as a teaching tool in orthopaedic surgery. Orthop. https://doi.org/10.1007/ s00132-020-03956-y

Publisher's note Springer Nature remains neutral with regard to jurisdictional claims in published maps and institutional affiliations. 